\title{
Poly(methyl methacrylate) capsules as an alternative to the "proof-of-concept" glass capsules used in self-healing concrete
}

Maria Araújo ${ }^{a, b}$, Sutima Chatrabhuti ${ }^{c}$, Stijn Gurdebeke ${ }^{a}$, Natalia Alderete $^{a, d}$, Kim Van Tittelboom $^{\mathrm{a}}$, Jean-Marie Raquez ${ }^{\mathrm{c}}$, Veerle Cnudde ${ }^{\mathrm{e}}$, Sandra Van Vlierberghe ${ }^{\mathrm{b}}$, Nele De Belie ${ }^{\mathrm{a}^{*}}$ and Elke Gruyaert ${ }^{\dagger}$

a Magnel Laboratory for Concrete Research, Department of Structural Engineering, Faculty of Engineering and Architecture, Ghent University, Tech Lane Ghent Science Park, Campus A, Technologiepark Zwijnaarde 904, 9052 Ghent, Belgium

b Polymer Chemistry and Biomaterials Group, Centre of Macromolecular Chemistry, Department of Organic and Macromolecular Chemistry, Faculty of Sciences, Ghent University, Krijgslaan 281, Building S4-bis, 9000 Ghent, Belgium

c Laboratory of Polymeric and Composite Materials (LPCM), Center of Innovation and Research in Materials and Polymers (CIRMAP), Mons University, Place du Parc 23, B-7000 Mons, Belgium

d LEMIT, CONICET, 52 entre 121 y 122 s/n, 1900, La Plata, Argentina

e Centre for X-ray Tomography/PProGRess, Department Geology and Soil Science, Faculty of Sciences, Ghent University, Krijgslaan 281, S8, 9000 Ghent, Belgium

${ }^{\dagger}$ Structural Mechanics and Building Materials, Technology Cluster Construction, Department of Civil Engineering, KU Leuven, Gebroeders De Smetstraat 1, 9000 Ghent, Belgium

* Correspondence to: Nele De Belie, Magnel Laboratory for Concrete Research, Department of Structural Engineering, Faculty of Engineering and Architecture, Ghent University, Tech Lane Ghent Science Park, Campus A, Technologiepark Zwijnaarde 904, 9052 Ghent, Belgium. E-mail: nele.debelie@ugent.be 


\section{Abstract}

3 Development of suitable capsules is essential to achieve self-healing by encapsulation. In the

4 context of self-healing concrete, capsules that can be easily mixed into concrete and release 5 the healing agent when cracking occurs are ideally required. The optimization of these 6 properties would allow for a successful implementation at large scale in practical (concrete) applications. In the present work, the suitability of polymeric cylindrical capsules made of

8 poly(methyl methacrylate) (PMMA) to carry healing agent in self-healing concrete has been 9 evaluated. An innovative method to assess more easily the capsules survival during concrete 10 mixing was developed. This method is based on the evaluation of the setting behavior of 11 concrete containing capsules filled with setting accelerator. Capsules with a wall thickness of $120.7 \mathrm{~mm}$ were able to resist the concrete mixing process and to rupture at relatively small crack 13 widths $(116 \mu \mathrm{m})$ after applying a surface treatment to increase the adhesion between the capsules and the cementitious matrix. Next, the self-healing efficiency of the encapsulation materials (glass or PMMA) was evaluated on real-scale concrete beams. The results showed that cracked concrete beams with mixed-in capsules (glass or PMMA) filled with waterrepellent agent showed higher resistance against chloride ingress compared to plain cracked concrete beams. PMMA capsules showed a lower self-healing efficiency (in relation to chloride ingress) compared to glass due to a less favorable distribution of the capsules in the concrete. However, concrete containing glass capsules is susceptible towards alkali-silica reaction.

21 Although optimization of the PMMA capsules is still necessary to improve their distribution in concrete and achieve higher self-healing efficiency, the obtained results indicate that these capsules could be a promising solution towards self-healing concrete.

26 Keywords: self-healing concrete, poly(methyl methacrylate), cylindrical capsules, cracks

\section{Introduction}


29 Polymeric healing agents have the ability to seal cracks and to bond the crack faces together. 30 Up to now, most healing agents are supplied to the cracks using spherical [1-8] or cylindrical 31 capsules [9-14], hollow fibers [15, 16] or vascular systems [17, 18]. In an encapsulation-based self-healing system, the capsules are randomly dispersed within the matrix so when cracks develop, some of these capsules are crossed by the crack resulting in rupture and subsequent release of the healing agent into the crack through capillary action. Certain criteria such as protection of the healing agent for a long time (up to several years) and the ability to release the content upon crack formation should be met by the capsule material. Moreover, capsules that can resist the concrete mixing process (i.e. high impact of the mixer and aggregates on the capsules and high shear stress exposure) are highly desired. As a result, the concrete production process would not be too much affected and the processing cost would not increase. Hence, self-healing concrete could effectively become valorized and interesting towards industrial application.

Most research has mainly focused on the development of organic spherical microcapsules or the use of cylindrical capsules (e.g. glass) to encapsulate the healing agent. Ureaformaldehyde (UF), gelatin, silica, melamine-urea-formaldehyde (MUF), phenol-formaldehyde (PF) and polyurethane (PU) microcapsules have been often used to encapsulate different healing agents in order to realize self-healing of cementitious materials [4-7, 19, 20]. Typically for spherical capsules the capsule diameters reported in literature range from $5 \mu \mathrm{m}$ to $5 \mathrm{~mm}$. One of the main concerns with the use of spherical microcapsules in concrete is that they can only sequester a very limited amount of healing agent and therefore become rapidly exhausted with increasing crack width. On the contrary, large crack volumes can be healed with cylindrical

51 capsules and their fracture probability upon concrete cracking is possibly higher. However, it is less probable that they would resist the mixing forces during mixing of concrete [21]. While

53 some authors proposed to increase the probability to survive casting and mixing of brittle 54 capsules (i.e. glass and ceramic) by applying a cement paste coating [22], others have 55 attempted to develop polymeric capsules with switchable mechanical properties so they can 
resist the mixing forces and break upon crack formation $[9,10]$. Due to their inertness to the healing agent and brittle nature (i.e. can be ruptured easily), hollow glass tubes have mostly been used for proof-of-concept experiments to investigate the self-healing efficiency of liquid healing agents [11-14, 23]. Most of the glass capsules used up to now would probably not resist the concrete mixing process without protection. Therefore, these glass capillaries are typically carefully placed inside mortar or concrete. More recently, Feiteira [24] showed that thicker glass capsules $(0.80$ to $1.5 \mathrm{~mm})$ can resist the concrete mixing process. However, one main concern with the use of glass capsules in concrete is that they might induce alkali-silica reactions (ASR) if a high amount of alkali is present in the cementitious matrix. Polymeric tubular capsules can be an alternative to the glass capsules as they are likely easier (and cheap) to manufacture in larger quantities. Moreover, polymeric materials can be found and designed with a wide range of mechanical properties which could possibly facilitate to develop capsules that can fulfill the two contradictory requirements: brittleness for rupturing when a crack forms and high flexibility and impact resistance to have a good survival probability when mixed with concrete. Hilloulin et al. [10] used polymeric materials which were brittle at room temperature and characterized by a relatively low glass transition temperature (i.e. $T_{g}$ between 59 and $105^{\circ} \mathrm{C}$ ) to prepare hollow tubes. By heating (above $\mathrm{T}_{\mathrm{g}}$ ) the tubes beforehand, their survival probability during concrete mixing was increased. Gruyaert et al. [9] mixed various plasticizers with ethyl cellulose to extrude tubes with evolving brittleness due to leaching of the plasticizer. The capsules could easily survive the concrete mixing process but breakage upon crack formation was not achieved. Though some advances have been achieved during the development of encapsulation materials to obtain autonomous healing of cracks in cementitious materials, suitable and appropriate capsules for polymeric healing agents which can be applicable in practice have not yet been identified to date. The present work covers an 80 investigation on the suitability of poly(methyl methacrylate) (PMMA) as an alternative to 81 frequently used glass for capsules to apply at a large scale in practical concrete structures. 82 The selection of poly(methyl methacrylate) was based on its ability to rupture when crossed by small cracks $(100 \mu \mathrm{m})$ as demonstrated previously [25]. In this study, PMMA capsules with 
84 varying dimensions were obtained by extrusion and optimized to be able to resist to the 85 concrete mixing process and at the same time break when intersected by cracks. An innovative 86 method to assess more easily the capsules survival rate during concrete mixing is also 87 presented. The self-sealing/healing of the best suited PMMA capsules was then evaluated in 88 large concrete elements. Since one of the main limitations of these capsules is still their 89 incapability of keeping air/moisture curing healing agents from premature hardening before 90 release and healing takes place, a water repellent agent was selected to be used in 91 combination with these capsules to regain the impermeability of cracked concrete.

\section{Materials and Methods}

94

\subsection{Capsule design for self-healing concrete}

PMMA (Plexiglas $8909, M_{n}=38000 \mathrm{~g} / \mathrm{mol}$ ), used to extrude the hollow tubes, was supplied by

100 Evonik Performance Materials (Darmstadt, Germany).

101 To avoid hydrolysis, PMMA was dried under vacuum during $24 \mathrm{~h}$ at $60{ }^{\circ} \mathrm{C}$ before extrusion. A 102 laboratory-scale Brabender single screw extruder, equipped with a die with outer and inner 103 diameter respectively of $10 \mathrm{~mm}$ and $8 \mathrm{~mm}$, was used to obtain the PMMA hollow tubes.

104 The processing temperature and parameters used during the extrusion process are shown in 105 Table 1. Capsules with varying wall thickness were prepared by adjusting the conveyor speed. 106 107

Table 1 - Extrusion parameters and dimensions of the PMMA capsules.

\begin{tabular}{cccc}
\hline Processing temperature $\left({ }^{\circ} \mathbf{C}\right)$ & Screw speed $\left(\mathbf{m i n}^{-1}\right)$ & Torque $(\mathrm{Nm})$ & Die pressure (bar) \\
$235-225$ & 10 & 103 & 18.8 \\
\hline \multirow{2}{*}{ Conveyor speed $(\mathrm{m} / \mathbf{m i n})$} & \multicolumn{3}{c}{ Capsule dimensions } \\
\cline { 2 - 4 } & External diameter $(\mathrm{mm})$ & Wall thickness $(\mathrm{mm})$ & Length $(\mathrm{mm})$
\end{tabular}




\begin{tabular}{llll}
0.5 & $6.5 \pm 0.3$ & $0.7 \pm 0.1$ & 50 \\
1.0 & $5.9 \pm 0.6$ & $0.4 \pm 0.1$ & 50 \\
1.2 & $5.8 \pm 0.3$ & $0.2 \pm 0.1$ & 50 \\
\hline
\end{tabular}

110 The glass capsules used as reference materials had an external diameter of $5.0 \mathrm{~mm}$ and a

111 wall thickness of $0.8 \mathrm{~mm}$ and were obtained from Glasatelier Saillart BVBA (Meerhout, 112 Belgium).

113

$114 \quad$ 2.1.2 Capsule survival probability with respect to concrete mixing process

116 First, the survival probability of capsules in self-healing concrete produced at laboratory scale

117 was assessed by the previously described method of manual counting after concrete mixing

$118[9,10]$. Mixed-in capsules were inspected on their completeness after removal of the cement 119 paste by sieving. This facilitates the manual retrieval and counting of the intact capsules. The 120 survival probability was then calculated by relating the number of intact capsules to the original 121 number of capsules added to the concrete mix.

122 Different parameters influencing the survival rate of capsules were studied:

123 i. capsule material (PMMA vs. glass);

124 ii. capsule dimensions (i.e. wall thickness);

125 iii. concrete composition (traditional concrete (TC) with crushed aggregates vs. self126 compacting concrete (SCC) with rounded aggregates (Table 2)) and;

127 iv. concrete mixer (Creteangle forced action pan mixer (type SE/GB) with a maximum 128 capacity of $\sim 14$ I vs. Eirich vertical shaft mixer with rotating pan and maximum capacity of $50 \mathrm{I})$.

131 The same mixing procedure was used throughout the study and consisted of mixing the dry 132 components during one minute, followed by addition of the water and mixing for another 133 minute. Subsequently, the capsules were added and all components were mixed during two 134 additional minutes. 
Table 2 - Concrete compositions used for the mixing tests.

\begin{tabular}{lc}
\hline \multicolumn{2}{c}{ Traditional concrete (1 $\left.\mathbf{~}^{\mathbf{3}}\right)$} \\
\hline Components & $(\mathrm{kg})$ \\
Sand 0/5 & 664 \\
Crushed stones 2/6 & 450 \\
Crushed stones 6/20 & 760 \\
CEM I 52.5 N & 350 \\
Water & 165 \\
\hline \multicolumn{2}{c}{ Self-compacting concrete $\mathbf{( 1 \mathbf { ~ } ^ { \mathbf { 3 } } )}$} \\
\hline Components & $(\mathrm{kg})$ \\
Sand 0/5 & 853 \\
Gravel 2/8 & 370 \\
Gravel 8/16 & 328 \\
Limestone filler & 300 \\
CEM I 52.5 N & 300 \\
Water & 165 \\
Superplasticizer (Glenium 51) & $2.5(\mathrm{I})$ \\
\hline
\end{tabular}

137

138

139 Since the method relying on counting the intact capsules is time-consuming and not practically

140 applicable for larger concrete mixes containing hundreds of capsules, alternative methods

141 were investigated, based on the evaluation of the setting behavior of concrete containing

142 capsules filled with set accelerator. If the effect of a given amount of set accelerator on certain

143 concrete properties is known, measuring of those concrete properties allows to back-calculate

144 the amount of set accelerator in the mix and hence the amount of capsules that have been

145 broken.

146 Therefore, first a calibration curve showing the influence of the amount of set accelerator on

147 the setting time of concrete was formulated. Then, concrete mixes containing different amounts

$148(0,0.25,0.5,1,1.2$ and 1.5 wt $\%$ vs. cement weight) of set accelerator (SIKA FS1) were

149 produced. The setting was monitored by performing (i) penetrometer tests and (ii) ultrasonic

150 (US) P-wave transmission measurements. The mixing procedure used was the same as

151 described previously, however, in these tests a self-compacting concrete (SCC) mix was used

152 since the fresh concrete had to be sieved to perform the penetrometer tests and this is more

153 convenient for SCC mixes than for traditional concrete mixes with a water-to-cement ratio of

$154 \quad 0.5$ and without plasticizers. The SCC mix composition used is shown in Table 2. 
155 The penetrometer tests were performed using the procedure described in the standard ASTM $156 \mathrm{C} 403$, but the concrete was sieved on a $4 \mathrm{~mm}$ sieve instead of a $4.75 \mathrm{~mm}$ sieve as prescribed 157 by ASTM C403 in order to eliminate the coarse aggregates and capsules. Initial and final 158 setting times were determined at a penetration resistance value of respectively 3.5 and 27.6 159 MPa.

160 The FreshCon system developed at the University of Stuttgart [26] was used to perform the 161 US measurements. The parameter studied was the P-wave velocity, determined based on the 162 detection of the onset time of the signal with the AIC picking algorithm taking into account the 163 time delay due to the travel of the pulse through hardware, sensors and container walls. 164 Penetrometer tests and continuous US measurements were executed in a climate room at a temperature of $20^{\circ} \mathrm{C}$ and a relative humidity of $60 \%$.

166 Next, SCC mixes containing encapsulated set accelerator (1 wt\% vs. cement weight) were 167 produced and the setting behavior was monitored. This $1 \mathrm{wt} \%$ amount corresponded to the 168 total amount of accelerator contained by all the capsules. The number of capsules added 169 varied slightly depending on the capsule type, since the amount of set accelerator that can be 170 stored inside one single capsule depends on its internal diameter.

171 Based on the calibration curve, the amount of set accelerator released (due to damage of the capsules) was determined, giving an indication of the number of capsules which had survived

173 the mixing process. Moreover, a part of the concrete mixes ( $10 \mathrm{I})$ was inspected manually to 174 additionally assess the survival probability by the method relying on counting the number of 175 intact capsules after mixing.

176 The mix composition (except the accelerator or capsule content), mix procedure, test 177 conditions (e.g. temperature) and testing procedures were kept constant during the calibration 178 and the effective tests.

179 2.1.3 Capsule breakage upon crack formation

181 In a previous study [25], it was shown that the PMMA capsules could be broken when 182 intersected by a crack. However, in the same study, to ensure that the capsules would not slip 
183 during crack formation, the ends of the capsules were heated and bent to create hooks. In 184 addition, the capsules were sanded perpendicular to their length to improve the bond with the cementitious matrix. As the hooked ends could create additional weak points of breakage during concrete mixing and the latter is very difficult and time-consuming to implement in reality, in the present work, the rupture capability upon crack formation has been evaluated, of

188 PMMA capsules that were either non-treated or treated by use of alternative strategies 189 compatible with translation to actual, real-life applications. Five different treatments were 190 considered as indicated in Figure 1: (A) the capsules were sanded perpendicular to their 191 length to create a rough surface and to increase the bond to the matrix; (B) a sand layer was 192 applied to both ends of the capsules to anchor the capsules and avoid slippage; (C) a coarse surface was created by applying a sand layer at one side of the capsule to increase adhesion

194 and to prevent capsules from becoming pulled out from the matrix; (D) a combination of 195 treatments $\mathrm{A}$ and $\mathrm{C}$ to further improve the adhesion to matrix and; $\mathrm{E}$ ) a combination of 196 treatments $\mathrm{A}$ and $\mathrm{B}$.

197 Since capsules with a wall thickness of 0.2 and $0.4 \mathrm{~mm}$ could not survive the concrete mixing 198 process (section 3.1), only capsules with a wall thickness of $0.7 \mathrm{~mm}$ were selected for further 199 testing.

200 To determine the crack width at breakage, mortar specimens with dimensions of $40 \mathrm{~mm} \times 40$ $201 \mathrm{~mm} \times 160 \mathrm{~mm}$ containing one single capsule, positioned in the middle of the specimen at 202 approximately $1.3 \mathrm{~cm}$ from the bottom, were casted.

203 Based on the results of the survival tests, only capsules with a wall thickness of $0.7 \mathrm{~mm}$ (outer 204 diameter $=6.5 \mathrm{~mm}$, length $=50 \mathrm{~mm}$ ) were chosen for testing. The capsules were filled with 205 water and sealed with hot glue at the ends. The mortar mix consisted of CEM I 52.5N with a 206 water-to-cement ratio of 0.5 and a sand-to-cement ratio of 3 and were prepared according to 207 the European Standard EN 196-1.

208 Cracking of the mortar prisms was performed at the age of 14 days by loading the samples in 209 a three-point-bending test. A linear variable differential transformer (LVDT) positioned at the 
210 bottom side of the specimen as described in [25] was used to measure the crack width. The

211 crack width was increased at a speed of $1 \mu \mathrm{m} \cdot \mathrm{s}^{-1}$ up to $400 \mu \mathrm{m}$.

215 The ability of the PMMA capsules (wall thickness $=0.7 \mathrm{~mm}$, outer diameter $=6.5 \mathrm{~mm}$, length

$216=50 \mathrm{~mm}$ ) to release their content upon crack formation was evaluated via a capillary water 217 absorption test by determining the regain in impermeability of cracked samples. The PMMA 218 capsules were sanded in the direction perpendicular to their length as described before. Glass 219 capsules (wall thickness $=0.8 \mathrm{~mm}$, outer diameter $=5.0 \mathrm{~mm}$, length $=50 \mathrm{~mm}$ ) were also 220 considered as reference materials.

221 The capsules were filled with a water-repellent agent (which renders the crack faces 222 impermeable) and embedded in mortar. Each mortar specimen contained one capsule, 223 positioned in the middle plane and at a height of $1.3 \mathrm{~cm}$, and was prepared according to the 224 procedure described in the previous section.

225 At the age of 14 days, the mortar specimens were cracked via a crack width controlled 3-point226 bending test (as described in section 2.1.3). The crack width was increased at a speed of 1 $227 \mu \mathrm{m} . \mathrm{s}^{-1}$ until a width of $250 \mu \mathrm{m}$ was obtained. The capillary water absorption test was performed 2282 days after cracking.

229 The capillary water absorption measurements were conducted as described earlier [27]. The 230 sorption coefficients were determined from the slope of the curves obtained by plotting the 231 water uptake as a function of the square root of time, according to the European Standard EN 23213057.

\subsection{Capsule performance in a large-scale lab test}

2.2.1 Concrete beams with(-out) capsules 
238 To validate the self-sealing efficiency of the capsules in large concrete elements, three real239 scale concrete beams $(250 \mathrm{~cm} \times 40 \mathrm{~cm} \times 20 \mathrm{~cm})$ reinforced with $4 \varnothing 10 \mathrm{~mm}$ ribbed steel bars 240 were made. Two of them contained self-sealing properties provided by either PMMA (wall 241 thickness $=0.7 \mathrm{~mm}$, outer diameter $=6.5 \mathrm{~mm}$, length $=50 \mathrm{~mm}$ ) or glass capsules (wall 242 thickness $=0.8 \mathrm{~mm}$, outer diameter $=5.0 \mathrm{~mm}$, length $=50 \mathrm{~mm})$. The capsules were sealed at 243 one end with hot glue (PMMA) or epoxy resin (glass), filled by means of a needle with a water244 repellent agent and sealed again at the other end. Moreover, the PMMA capsules were sanded 245 in a direction perpendicular to their length (as aforementioned).

246 The third beam was a reference beam without capsules. The concrete mixes consisted of self247 compacting concrete (Table 2) and were prepared using a vertical shaft mixer with a maximum 248 capacity of $200 \mathrm{~L}$. The concrete composition was the same for all the mixes but for the concrete beams with self-healing properties, PMMA or glass capsules were added in the last 2 minutes

250 of the mixing process. Since it was observed that PMMA capsules tend to float as a result of 251 their relatively low density, it was decided to cast the concrete in 2 steps. First, a concrete mix 252 containing the capsules with a concentration of approximately 22 capsules per liter of concrete 253 (3250 capsules in 150 I concrete) was made and poured into the mould, forming a layer of 12 $\mathrm{cm}$. Afterwards, another mix without capsules was prepared and placed into the mould on top of the previous layer. Although, the glass capsules do not tend to float, the beam containing these capsules was cast in the same manner in order to have the same conditions.

257 After demoulding, the beams were stored in a standard laboratory environment until the time 258 of testing.

2.2.2 Crack formation

263 At the age of 14 days, 6 cracks with varying crack widths were made in each beam using a 3264 point-bending test set-up. The cracks were created consecutively (one crack per day) by moving the 3-point-bending set-up over the length of the beam (Figure 2). Notches were swan 
266 at the corners of the beam in the middle of the span of the 3-point-bending set-up prior to

267 loading. Localized cracks were then created by loading the beams in a stepwise fashion while

268 the crack width was measured using an electronic ruler. When a predefined crack width was

269 reached (Table 3), the notches were filled with a shrink-free repair mortar in order to keep the

270 crack open. The beams were then unloaded after sufficient hardening of the repair mortar. The

271 crack widths obtained after unloading for each beam were determined afterwards using an

272 optical microscope. For each crack, crack width measurements were performed at 6 positions

273 (at the crack mouth) over the length of the crack.

274

Table 3 - Max crack width at loading for each concrete beam.

\begin{tabular}{ccccc}
\hline \multirow{2}{*}{ Crack } & Predefined & \multicolumn{3}{c}{ Max crack width at loading (mm) } \\
\cline { 3 - 5 } & width (mm) & REF & PMMA & Glass \\
\hline 1 & 0.40 & 0.42 & 0.42 & 0.42 \\
2 & 0.60 & 0.53 & 0.55 & 0.54 \\
3 & 0.35 & 0.36 & 0.36 & 0.39 \\
4 & 0.5 & 0.48 & 0.49 & 0.48 \\
5 & 0.6 & 0.61 & 0.61 & 0.67 \\
6 & 0.45 & 0.44 & 0.44 & 0.45 \\
\hline
\end{tabular}

2.2.3 Chloride ingress measurements

The self-healing efficiency of the concrete beams with embedded capsules was evaluated by

281 determining the resistance of the self-healed concrete against chloride ingress. To this, the 282 beams were positioned slightly tilted with the cracks in the upper surface and a $3 \mathrm{wt} \% \mathrm{NaCl}$ 283 solution was flown over the beams during 24 uninterrupted hours per week. This 1 day wet 2846 days dry cycle was repeated during 6 consecutive weeks. Prior to exposure, all sides of the beams except the top and bottom surfaces were covered with a waterproof aluminum foil so 286 that only the top surface was exposed to the chloride solution.

287 To determine the chloride ingress, 2 cores with a diameter of $150 \mathrm{~mm}$, with a crack inside, 288 were obtained from each beam. Subsequently, each core was split along the crack surface 
and one half was then used to measure the chloride ingress. This was done by grinding off

290 material at various depths $(5,25,50$ and $85 \mathrm{~mm})$ in $2 \mathrm{~mm}$ layers perpendicular to the crack

291 face. In addition, material was ground from the exposed surface downwards. Concrete 292 powders were collected from ten layers for each zone and dried in an oven at $95^{\circ} \mathrm{C}$ for at least 2937 days. A schematic representation of the ground surfaces is given in Figure 3. As can be 294 seen, for each core, the position of the ground areas on the crack face varies slightly. This is 295 due to the fact that for some of the cores an irregular crack face was obtained after splitting 296 and a relatively flat area had to be chosen in order to be able to grind off material.

297 The total chloride concentration per ground layer was determined by an acid-soluble extraction 298 in a nitric acid solution followed by a potentiometric titration against silver nitrate [28].

2.2.4 Capsule distribution (by X-ray micro-tomography)

After testing, multiple cores were drilled from the beams for further analysis. One core (with a diameter of $150 \mathrm{~mm}$ ) of each beam containing glass or PMMA capsules was scanned at the Center for X-ray Tomography of Ghent University (UGCT) using the X-ray micro-tomography $(\mu \mathrm{CT})$ [29] cone beam set-up of the High-Energy CT system Optimized for Research (HECTOR) scanner [30]. For each scan, 913 projections were acquired over an angle of 360‥

307 To reduce beam hardening, low energetic X-rays at the source were blocked using a cupper 308 filter of $0.5 \mathrm{~mm}$ thickness. The X-ray tube provided a voltage of $200 \mathrm{kV}$ with a power of $30 \mathrm{~W}$. 309 The source-detector distance was $1047 \mathrm{~mm}$ and the source-object distance was $373 \mathrm{~mm}$, resulting in a voxel size of $140 \mu \mathrm{m}$. The in-house developed software [31, 32] was used to reconstruct the raw data into cross-sectional images (slices). These images were then used to generate a 3D rendering (using VGStudioMax) of the specimens which could be used to

313 assess the distribution of the capsules in the concrete cores and possible leakage of healing 314 agent from the capsules. 
319 The resistance of the concrete containing glass capsules to the alkali-silica reaction (ASR) was determined using the accelerated Oberholster test method. Six cylinders (age: 6 months) with a diameter of $50 \mathrm{~mm}$ and approximately $160 \mathrm{~mm}$ height were taken from the beam containing

322 glass capsules and placed in the measurement set-up. One steel reference sample was also 323 placed inside the container in order to exclude expansions due to external factors (e.g. 324 temperature variations). The dial gauges were then installed on top of the samples and the 325 container was filled with water. The water was heated up to $80^{\circ} \mathrm{C}$ and the cylinders were kept 326 in the water for $24 \mathrm{~h}$. Afterwards, the water was replaced by a $1 \mathrm{M} \mathrm{NaOH}$ solution and a reference measurement was taken $1 \mathrm{~h}$ after the temperature of this solution had been stabilized at $80^{\circ} \mathrm{C}$. The expansion of the test and reference specimens was measured for a period of 14 days.

\section{Results and Discussion}

\subsection{Survival probability to the concrete mixing process}

Figure 4A presents the calibration curves based on the penetrometer tests performed on mixes containing a known amount of set accelerator. As can be clearly seen, the initial and final setting times decrease with increasing dosage of set accelerator in the mix. A linear relationship between the initial/final setting time and set accelerator content could be drawn as

339 given by equations (1) and (2), respectively. While the $\mathrm{r}^{2}$-values are still acceptable $(0.75$ 340 0.83), the repeatability, as observed for the reference mix without set accelerator, is limited. 341 Although, the penetrometer test conditions (i.e. temperature during the test) were kept 342 constant, the concrete raw components were not acclimatized and concrete mixing did not 343 take place in a temperature and humidity controlled room. A variation in temperature during 
344 concrete mixing of about $5^{\circ} \mathrm{C}$ was monitored, which could explain the variation obtained for 345 the reference mixtures. In future tests, this aspect should be taken into account.

Initial setting time $[$ hours $]=-1.265 \times$ accelerator content $[w t . \%]+4.66$

Final setting time $[$ hours $]=-1.243 \times$ accelerator content $[w t . \%]+6.782$

Figure $4 \mathrm{~B}$ presents the setting time obtained for the mixes containing the various capsules filled with 1 wt $\%$ of set accelerator. Taking into account the initial content of $1 \mathrm{wt} \%$, the survival ratio for the different types of capsules in the SCC mixes could be determined. The results are presented in Table 4 and discussed in the sections below.

The UPV calibration curves are shown in Figure 5A. The acceleration of the setting behavior for mixes with increasing dosages of the set accelerator is clearly visible. The dormant period decreases and UPV-values at early age increase by the addition of set accelerator as also reported by [33]. As can be seen in Figure 5B, exact determination of the capsule's survival ratio is quite difficult based on the graphs solely. A rough estimate of the survival ratio for each of the PMMA capsules is given in Table 4.

361 Table 4 summarizes the results on survival of glass and PMMA capsules in concrete, 362 determined by counting manually the number of intact capsules after mixing, and the 363 alternative novel methods (i.e. based on released amount of set accelerator as estimated from 364 penetrometer and US measurements).

365 Capsule dimensions have a clear effect on the survival probability. As anticipated, the survival 366 probability of the PMMA capsules increases as the wall thickness of the capsules increases. 367 This is also expected for glass capsules as reported by [24]. These results indicate that thicker 368 capsules can be more easily incorporated into concrete. However, this might lead to a lower 369 self-sealing efficiency as the rupture probability upon cracking of thicker capsules will become 370 lower. Moreover, less healing agent can be sequestered in one capsule. Furthermore, the 371 results in Table 4 show the remarkable influence of the concrete composition and mixing 
372 equipment on the resistance of the capsules towards the mixing process. The mixing forces

373 using an Eirich vertical shaft mixer appear to be less aggressive as considerably more

374 capsules survived the mixing process when this mixer was used. This was particularly 375 noticeable for PMMA capsules with a wall thickness of $0.7 \mathrm{~mm}$, with the survival ratio 376 increasing from 40 to $87 \%$.

377 The stresses induced on the capsules are also lower for a SCC than for a TC mix and this is 378 clearly reflected in the survival percentages of the glass capsules and PMMA capsules with a 379 wall thickness of $0.2 \mathrm{~mm}$ and $0.4 \mathrm{~mm}$.

380 The alternative novel methods have been validated with the method of counting the intact 381 capsules after concrete mixing. In general a good correspondence, except for PMMA capsules 382 with a wall thickness of $0.4 \mathrm{~mm}$, was obtained. However, the use of the penetrometer seems 383 at the moment the most promising technique. The penetrometer test is simple to execute and 384 analyse and the method is user-friendly. With regard to the US measurement, the test method 385 should be further optimized and the use of retarders or air-entrainers instead of set accelerators should be evaluated.

Table 4 - Survival ratio (\%) of the various types of capsules for the different methods used to determine the probability of survival during mixing.

\begin{tabular}{|c|c|c|c|c|c|c|c|c|}
\hline & \multicolumn{4}{|c|}{ Test parameters } & \multicolumn{4}{|c|}{ Survival ratio (\%) } \\
\hline & Concrete & $\begin{array}{c}\text { Mixe } \\
r\end{array}$ & $\begin{array}{c}\text { Volume } \\
\text { (liter) }\end{array}$ & Method & $\begin{array}{l}\text { Glass } \\
t=0.8\end{array}$ & $\begin{array}{l}\text { PMMA } \\
t=0.2\end{array}$ & $\begin{array}{l}\text { PMMA } \\
t=0.4\end{array}$ & $\begin{array}{l}\text { PMMA } \\
t=0.7\end{array}$ \\
\hline \multirow{2}{*}{ 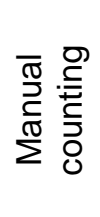 } & $\mathrm{TC}$ & a & 10 & $\begin{array}{l}\text { Manual } \\
\text { counting }\end{array}$ & 50 & 0 & 20 & 40 \\
\hline & $\mathrm{TC}$ & $b$ & 30 & $\begin{array}{l}\text { Manual } \\
\text { counting }\end{array}$ & $70^{[24]}$ & 0 & 20 & 87 \\
\hline ఏ & SCC & $b$ & 50 & $\begin{array}{c}\text { Manual } \\
\text { counting }\end{array}$ & 100 & 20 & 83 & 95 \\
\hline
\end{tabular}




\begin{tabular}{|c|c|c|c|c|c|c|c|}
\hline SCC & $b$ & 50 & $\begin{array}{l}\text { PM-initial } \\
\text { set }\end{array}$ & 100 & 0 & 40 & 100 \\
\hline SCC & $b$ & 50 & $\begin{array}{l}\text { PM-initial } \\
\text { set }\end{array}$ & 100 & 0 & 50 & 100 \\
\hline SCC & $b$ & 50 & US & ND & 0 & 0 & 75 \\
\hline
\end{tabular}

$\mathrm{t}=$ wall thickness in $\mathrm{mm} ; \mathrm{PM}=$ penetrometer; $\mathrm{US}=$ ultrasonic measurement (FreshCon)

$398 a=$ Creteangle forced action pan mixer (type SE/GB); $b=$ Eirich vertical shaft mixer with rotating pan

$399 \mathrm{ND}=$ not determined

400

401

\section{$402 \quad 3.2$ Crack width at breakage}

403

404 Since capsules with a wall thickness of 0.2 and $0.4 \mathrm{~mm}$ showed a low resistance towards 405 mixing in concrete, only capsules with a wall thickness of $0.7 \mathrm{~mm}$ were selected for further 406 testing. Typically, rupture of the capsules is visualized in the load-displacement graph obtained 407 during mechanical testing (characterized by a sharp drop in the load) (Figure 6) and is 408 sometimes associated with a characteristic sound. This drop in load was used to determine 409 the crack width at rupture of the capsules.

410 Figure 7 shows the crack width at rupture for the different treatments applied. Smooth, non411 treated capsules did not break when cracks with a width of $400 \mu \mathrm{m}$ were created. This can be 412 attributed to a poor adhesion of the smooth capsules to the cementitious matrix, which causes 413 the capsules to slip. When comparing the different surface treatments, capsules that were 414 sanded perpendicularly to their length (treatments A) ruptured at smaller crack widths (117 $415 \mu \mathrm{m})$.

416 Applying a sand layer to both ends of the capsules did not seem to improve the locking of the 417 capsules inside the mortar as 2 out of 3 capsules did not break during the test. Additionally, a 418 partial coating of the capsules with sand (treatment C) resulted in rupture of the capsules at a 419 crack width of about $240 \mu \mathrm{m}$, which is considerably above the expected crack size at breakage $420(100-150 \mu \mathrm{m})$ as reported by Šavija et al. [25]. Capsules which were surface-treated with 421 procedure $\mathrm{D}$ or $\mathrm{E}$ ruptured when crossed by an average crack width of 180 and $210 \mu \mathrm{m}$, 422 respectively. 
423 The results show that it is necessary to apply a surface treatment to the PMMA capsules in

424 order to induce rupture at crack sizes typically permitted by the reinforced concrete design 425 codes $(\sim 300 \mu \mathrm{m})$. Sanding the capsules (most practically feasible method) in a direction 426 perpendicular to their length was sufficient to achieve proper adhesion between the capsule 427 and the cementitious matrix, resulting in rupture of the capsules for similar crack sizes 428 compared to those previously verified for capsules with the same wall thickness (with hooked 429 ends) [25].

430

\subsection{Healing efficiency upon crack formation}

432

433 The sealing efficiency of the PMMA capsules after fracture was evaluated by means of a 434 capillary water absorption test. The mean water sorption as a function of the square root of 435 time and the absorption coefficients of each test series are shown in Figure 8. The crack size 436 (at the mouth) of the tested specimens ranged between 230 and $270 \mu \mathrm{m}$. The results of the 437 capillary water absorption tests on mortar prisms containing capsules filled with water-repellent agent (WRA) clearly showed that a lower water uptake was realized for the self-healed cracked samples. No significant differences were observed between the efficiency of glass and PMMA capsules. These results show that WRA can be used in combination with PMMA capsules to

441 regain the impermeability of cracked concrete. Since premature curing of one-component 442 air/moisture sensitive curable healing agents may occur when using polymeric capsules as 443 observed earlier by Hilloulin et al. [10] and Thao et al. [34], WRA can be used as an alternative 444 to these healing agents to reduce ingress of aggressive liquids.

3.4 Efficiency of the capsules in large concrete elements 
450 The main aim of this study was to investigate whether polymeric (PMMA) cylindrical capsules 451 could be used to obtain concrete with self-healing properties. The capsules should be able to 452 survive the concrete mixing process and release their content upon intersection by a crack. 453 Since PMMA capsules with a wall thickness of approximately $0.7 \mathrm{~mm}$ (outer diameter $=6.5$ $454 \mathrm{~mm}$ ) fulfilled these 2 requirements, the self-healing efficiency of these capsules on large 455 concrete elements was further investigated. Furthermore, glass capsules (wall thickness $=0.8$ $456 \mathrm{~mm}$, outer diameter $=5 \mathrm{~mm}$ ) were also tested and considered as reference capsules.

457 In order to be able to compare the crack sealing efficiency of both encapsulation materials, 458 cracks with similar width were aimed for. The average crack widths at the crack mouth obtained 459 after unloading of each beam are shown in Figure 9. It can be seen that cracks with similar 460 widths were obtained for the REF, PMMA and glass beams, except for crack 5 where a slightly 461 higher crack width was observed for the REF beam.

462 It should also be mentioned that during loading of the beams containing encapsulated healing 463 agent, leaking of the healing agent was detected, indicating that some capsules were crossed 464 by the crack and broke. The latter was more noticeable for the beam with glass capsules with 465 leaching out of WRA visible for all cracks. Given the brittle nature of glass (i.e. low elongation 466 at break) compared to PMMA, glass capsules have likely more probability to be broken when crossed by a crack in concrete. The glass capsules are expected to rupture when crossed by 468 cracks of $30 \mu \mathrm{m}$ width [24] which is well below the crack widths at which PMMA capsules can 469 be broken.

$470 \quad 3.4 .2$ Capsule distribution

472 High-resolution X-ray computed tomography $(\mu \mathrm{CT})$ was used to characterize the distribution 473 of the capsules in the self-healing concrete elements and leakage of WRA from the capsules 474 after fracture of the concrete.

475 Scanning concrete elements with a diameter of $150 \mathrm{~mm}$ is very close to the limit of the 476 HECTOR scanner capacity. Therefore, the resolution of the reconstructed images is limited. 
Figure 10A illustrates a horizontal slice through a concrete cylinder where an emptied capsule could be clearly identified. The capsules and the crack could be distinguished by selecting appropriate thresholds in OctopusAnalysis, after which a 3D rendering of the different cores was made. Since the crack is only represented by a few voxels within the reconstructed images, it was impossible to visualize it correctly in the 3D rendering. Moreover, as the healing agent (WRA) used in the large-scale experiments was absorbed by the concrete, crack filling with this fluid was undetectable on the $\mu \mathrm{CT}$ scans because of the limited resolution. The capsules were classified as empty or filled with healing agent based on the different grey levels of its contents observed on the $\mu \mathrm{CT}$ images. As air has a very low attenuation coefficient for X-rays compared to the surrounding concrete, it appears black on the reconstructed images. A capsule that has a black color is possibly filled with air instead of healing products and was classified as empty. On the contrary, in the capsules that were filled with healing agent an enclosed air bubble could be identified. When no air bubble can be identified, classifying a capsule as filled is much more difficult due to the limited difference in grey level of air and WRA. Using this method, each capsule was classified as empty or filled with healing agent and it was also established whether it was crossed by the crack or not. The 3D distribution of the capsules in the cores is shown in Figure 10B. The empty capsules that were crossed by the crack are depicted in red while the other capsules are illustrated in blue.

It can be seen that substantially more glass capsules are dispersed in the concrete core compared to the PMMA capsules (39 versus 19 capsules, respectively). Since the PMMA capsules showed a high survival ratio towards mixing it is unlikely that the lower amount of PMMA capsules present in the core compared to glass is due to breakage during concrete preparation. It is hypothesized that this is rather due to the tendency of the PMMA capsules to float, which resulted in a less homogeneous distribution of the capsules in the beam. One would expect that if the capsules float that they would be more concentrated in one layer. Although, the scanned core covered the complete height of the beam, this was not visible. An explanation can be that during concrete pouring the PMMA capsules were also floating 
504 towards the ends of the beams and the $\mu \mathrm{CT}$ analysis was performed on a core drilled away

505 from the edges of the beam (i.e. crack 4 (see Figure 2)).

506

507 3.4.3 Resistance of the self-healed concrete against chloride ingress

508

509 The experimentally determined chloride profiles for all cracked and healed samples in the

510 vicinity of the exposed surface are shown in Figure 11. It can be seen that for three of the

511 healed samples (Glass 1, PMMA 1 and PMMA 2), the chloride concentration is approximately

512 constant at every depth. When comparing with cracked concrete it is clear that the chloride

513 content is considerably reduced due to release of healing agent from the capsules. Next, a

514 similar chloride profile as those of the reference samples was observed for one of the samples

515 containing glass capsules (glass 2). This means that most likely no healing agent was released

516 from the capsules in the considered measuring zone.

517 The chloride profiles obtained at the crack surface are presented in Figure 12. First, a more 518 detailed investigation of the chloride profiles per group of samples (REF, Glass or PMMA) is 519 presented.

520 For the reference samples, the highest chloride concentrations at every depth are found in the

521 zone A. Since this section was ground right next to the exposed surface, the chlorides 522 penetrated through and perpendicular to the crack. This can also explain the fluctuation in the 523 chloride contents observed in this zone. It can also be noticed that for REF 2 a higher chloride 524 concentration was found for a zone deeper inside the crack (i.e. area C) than an area close to 525 the exposure surface (i.e. area B). This is probably due to the presence of microcracks parallel 526 to the crack surface. These microcracks increase the interconnectivity between pores and thus 527 can increase the penetration of chlorides in areas located more distant from the exposure 528 surface.

529 The chloride ingress in the samples containing glass capsules is approximately constant, 530 regardless the layer depth (from $4 \mathrm{~mm}$ onwards) and the distance from the exposure surface, 531 except for zone A in Glass 2. In this sample, a considerably higher chloride content was 
532 measured at the position A. Visual investigation of the spread region of the water-repellent 533 agent (which gives a darker grey color) on the crack face from where material was ground 534 revealed that in this particular section no healing agent was seen, which could explain the 535 higher chloride concentration (Figure 13).

536 For the specimens containing PMMA capsules, PMMA 1 showed a chloride profile very similar

537 to the glass 1 profile for the sections $B, C$ and $D$. The chloride concentration in area $A$ is 538 considerably higher since this zone comprised a zone without WRA. Relatively high chloride 539 contents with similar magnitude of the reference samples were found for PMMA 2. Although, 540 the crack width in this sample is slightly higher, the insufficient resistance against chloride 541 penetration is mostly due to falling short of the healing mechanism as visual inspection of the 542 specimen showed that only one capsule released its content.

543 Overall, it can be seen that the chloride penetration is substantially lower in self-healed 544 samples compared to cracked reference concrete. However, the difference in chloride 545 penetration between cracked reference concrete and concrete containing PMMA capsules 546 was less pronounced, with one of the specimens showing low resistance to chloride ingress. 547 These results show that the ingress of chlorides is considerably reduced in areas where 548 healing agent was released from the capsules. This stresses the importance of having a 549 uniform distribution of the capsules to achieve higher sealing efficiencies.

550

$551 \quad 3.4 .4$ Alkali-silica reaction

553 Since glass capsules might induce alkali-silica reaction, the resistance of the concrete 554 containing glass capsules to the alkali-silica reaction was determined. Based on literature [35, 55536 , an expansion less than $0.1 \%$ was defined as the limit to consider the glass capsules as 556 non-reactive. Moreover, if the expansion values are within the range of $0.1-0.2 \%$, further 557 analysis is required and if the $0.2 \%$ value is exceeded, the concrete is considered alkali-silica 558 reactive. 
559 The evolution of the expansion in function of time of concrete samples containing glass

560 capsules is shown in Figure 14. The limit values (i.e. $<0.1 \%$ : not reactive (green zone); $0.1-$ $5610.2 \%$ : undefined and $>0.2 \%$ : reactive) are also indicated. As can been seen, the expansion 562 exceeded the $0.1 \%$ limit after 6 days. Since the expansion is significantly higher than $0.2 \%$ 563 after 7 days, the reactivity of the glass capsules with concrete is confirmed.

564

\section{Conclusions}

566

567 The present work has evaluated whether or not polymeric capsules constituted of PMMA can 568 be used to introduce self-healing properties in concrete. The fitness of the PMMA capsules 569 was assessed by determining their robustness during concrete mixing and their probability for 570 breakage to occur upon intersection by a crack in concrete. However, it is necessary to apply 571 a surface treatment to the capsules to induce rupture for relatively small crack widths in concrete $(\sim 100 \mu \mathrm{m})$. The combined outcome from these experimental tests revealed that

573 PMMA capsules with a wall thickness of approximately $0.7 \mathrm{~mm}$ and an outer diameter of about

$5746.5 \mathrm{~mm}$ are the most promising capsules to apply at larger scale.

575 As alternative to the method of counting manually the number of capsules intact after mixing, 576 a more straightforward method to determine the capsules survival probability during concrete 577 preparation was successfully developed. In this novel method, the setting properties of concrete with encapsulated set accelerator were compared with a calibration curve of setting 579 times in function of set accelerator content.

580 Real-scale tests revealed that the resistance of cracked concrete against chloride could be 581 increased for concrete made with self-healing properties. In these tests, glass capsules 582 performed better compared to PMMA as a result of a more uniform distribution of the capsules. 583 However, expansion results (Oberholster test) showed that the concrete containing glass 584 capsules is susceptible towards the alkali-silica reaction.

585 In summary, polymeric capsules constituted of poly(methyl methacrylate) seem to be a 586 promising alternative for the glass capsules that have been used in proof-of-concept 
experiments to encapsulate healing agent for self-healing concrete. However, future work should be performed to improve the distribution of PMMA capsules in concrete in order to achieve higher healing efficiencies.

\section{Acknowledgments}

592

593 This research was carried out within the M-ERA.net project "Encapsulation of polymeric 594 healing agents in self-healing concrete: capsule design", funded by VLAIO (Flanders 595 Innovation \& Entrepreneurship) and DGO6 (Walloon Direction Générale Opérationnelle de 596 l'Économie, de l'Emploi et de la Recherche). The authors would like to acknowledge these 597 foundations for financial support.

598 At the time when the experiments were performed, Kim Van Tittelboom was a postdoctoral 599 fellow of the Research Foundation - Flanders (FWO) (project number 12A3314N) and she 600 acknowledges its support.

601

\section{References}

603

604 1. Cailleux E, Pollet V: Investigations on the development of self-healing properties in 605 protective coatings for concrete and repair mortars. In: 2nd Internatinal Conference on 606 Self-healing Materials. Chicago; 2009.

607 2. Yang Z, Hollar J, He X, Shi X: A self-healing cementitious composite using oil core/silica 608 gel shell microcapsules. Cement and Concrete Composites 2011, 33(4):506-512.

609 3. M Pelletier M, Brown R, Shukla A, Bose A: Selfhealing Concrete with a $610 \quad$ Microencapsulated Healing Agent; 2011.

611 4. Dong B, Fang G, Ding W, Liu Y, Zhang J, Han N, Xing F: Self-healing features in 612 cementitious material with urea-formaldehyde/epoxy microcapsules. Construction and 613 Building Materials 2016, 106:608-617.

614 5. Gilford J, Hassan MM, Rupnow T, Barbato M, Okeil A, Asadi S: Dicyclopentadiene and 615 Sodium Silicate Microencapsulation for Self-Healing of Concrete. Journal of Materials in 616 Civil Engineering 2014, 26(5):886-896. 
617 6. Tan NPB, Keung LH, Choi WH, Lam WC, Leung HN: Silica-based self-healing 618 microcapsules for self-repair in concrete. Journal of Applied Polymer Science 2016, 619 133(12):n/a-n/a.

620 7. Wang X, Sun P, Han N, Xing F: Experimental Study on Mechanical Properties and 621 Porosity of Organic Microcapsules Based Self-Healing Cementitious Composite. $622 \quad$ Materials 2017, 10(1).

623 8. Li W, Zhu X, Zhao N, Jiang Z: Preparation and Properties of Melamine Urea624 Formaldehyde Microcapsules for Self-Healing of Cementitious Materials. Materials $625 \quad 2016,9(3): 152$.

626 9. Gruyaert E, Van Tittelboom K, Sucaet J, Anrijs J, Van Vlierberghe S, Dubruel P, De 627 Geest BG, Remon JP, De Belie N: Capsules with evolving brittleness to resist the 628 preparation of self-healing concrete. $20162016,66(323)$.

629 10. Hilloulin B, Van Tittelboom K, Gruyaert E, De Belie N, Loukili A: Design of polymeric 630 capsules for self-healing concrete. Cement and Concrete Composites 2015, 55:298-307.

11. Dry CM: Three designs for the internal release of sealants, adhesives, and waterproofing chemicals into concrete to reduce permeability. Cement and Concrete Research 2000, 30(12):1969-1977.

12. Lark R, Joseph C, Isaacs B, Gardner D, Jefferson A: Experimental investigation of adhesive-based self-healing of cementitious materials, vol. 62; 2010.

13. Wang J, Van Tittelboom K, De Belie N, Verstraete W: Use of silica gel or polyurethane immobilized bacteria for self-healing concrete. Construction and Building Materials 2012, 26(1):532-540.

14. Van Tittelboom K, De Belie N, Van Loo D, Jacobs P: Self-healing efficiency of cementitious materials containing tubular capsules filled with healing agent. Cement and Concrete Composites 2011, 33(4):497-505.

15. Li VC, Lim YM, Chan Y-W: Feasibility study of a passive smart self-healing cementitious composite. Composites Part B: Engineering 1998, 29(6):819-827.

16. Pang JWC, Bond IP: A hollow fibre reinforced polymer composite encompassing selfhealing and enhanced damage visibility. Composites Science and Technology 2005, 65(11):1791-1799.

17. Sangadji S, Schlangen HEJG: Porous network concrete: A new approach to make concrete structures self-healing using prefabricated porous layer (abstract). In.; 2011.

18. Minnebo P, Thierens G, De Valck G, Van Tittelboom K, De Belie N, Van Hemelrijck D, Tsangouri E: A Novel Design of Autonomously Healed Concrete: Towards a Vascular Healing Network. Materials 2017, 10(1). 
19. Litina C, Kanellopoulos A, Al-Tabbaa A: Alternative repair system for concrete using microencapsulated healing agents. In: Concrete Solutions: Proceedings of Concrete Solutions, 5th International Conference on Concrete Repair: 97-103, 2014.

20. Lv L, Schlangen E, Yang Z, Xing F: Micromechanical Properties of a New Polymeric Microcapsule for Self-Healing Cementitious Materials. Materials 2016, 9(12).

21. Van Tittelboom K, De Belie N: Self-Healing in Cementitious Materials-A Review. Materials 2013, 6(6):2182-2217.

659

22. Van Tittelboom K, Tsangouri E, Van Hemelrijck D, De Belie N: The efficiency of selfhealing concrete using alternative manufacturing procedures and more realistic crack patterns. Cement and Concrete Composites 2015, 57:142-152.

23. Feiteira J, Gruyaert E, De Belie N: Self-healing of moving cracks in concrete by means of encapsulated polymer precursors. Construction and Building Materials 2016, 102:671678.

24. Feiteira J: Self-Healing Concrete Encapsulated polymer precursors as healing agents for active cracks. Doctoral dissertation. University of Ghent; 2017.

25. Šavija B, Feiteira J, Araújo M, Chatrabhuti S, Raquez J-M, Van Tittelboom K, Gruyaert E, De Belie N, Schlangen E: Simulation-Aided Design of Tubular Polymeric Capsules for Self-Healing Concrete. Materials 2017, 10(1):10.

26. Robeyst N, Gruyaert E, Grosse CU, De Belie N: Monitoring the setting of concrete containing blast-furnace slag by measuring the ultrasonic $p$-wave velocity. Cement and Concrete Research 2008, 38(10):1169-1176.

27. Araújo M, Van Vlierberghe S, Feiteira J, Graulus G-J, Van Tittelboom K, Martins JC, Dubruel P, De Belie N: Cross-linkable polyethers as healing/sealing agents for selfhealing of cementitious materials. Materials \& Design 2016, 98:215-222.

28. Song M: Chloride Penetration and Service Life Prediction of Cracked Self-Compacting Concrete. PhD thesis. Ghent; 2012.

29. Cnudde V, Boone MN: High-resolution X-ray computed tomography in geosciences: A review of the current technology and applications. Earth-Science Reviews 2013, 123(Supplement C):1-17.

30. Bert M, Manuel D, Denis Van L, Matthieu NB, Loes B, Elin P, Veerle C, Luc Van H: HECTOR: A 240kV micro-CT setup optimized for research. Journal of Physics: Conference Series 2013, 463(1):012012.

31. Vlassenbroeck J, Dierick M, Masschaele B, Cnudde V, Van Hoorebeke L, Jacobs P: Software tools for quantification of X-ray microtomography at the UGCT. Nuclear Instruments and Methods in Physics Research Section A: Accelerators, Spectrometers, Detectors and Associated Equipment 2007, 580(1):442-445. 
32. Brabant L, Vlassenbroeck J, De Witte Y, Cnudde V, Boone MN, Dewanckele J, Van Hoorebeke L: Three-Dimensional Analysis of High-Resolution X-Ray Computed Tomography Data with Morpho+. Microscopy and Microanalysis 2011, 17(2):252-263.

33. De Belie N, Grosse CU, Kurz J, Reinhardt HW: Ultrasound monitoring of the influence of different accelerating admixtures and cement types for shotcrete on setting and hardening behaviour. Cement and Concrete Research 2005, 35(11):2087-2094.

34. Thao TDP, Johnson TJS, Tong QS, Dai PS: Implementation of self-healing in concrete - Proof of concept. The IES Journal Part A: Civil \& Structural Engineering 2009, 2(2):116125.

35. Desmyter J PG, Demars P, Jacobs J: De alkali-silica reactie. WTCB Tijdschrift:3-17.

36. Gruyaert E, Maes M, De Belie N: Performance of BFS concrete: $k$-Value concept versus equivalent performance concept. Construction and Building Materials 2013, 47(Supplement C):441-455.

701

\section{Figures}

A

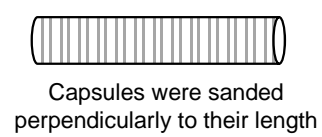

D

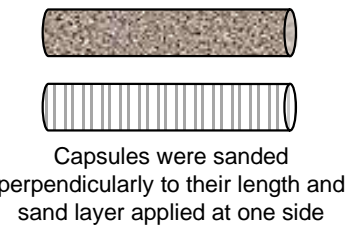

B

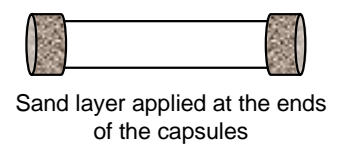

E

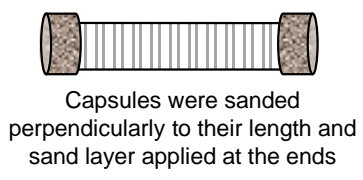

C
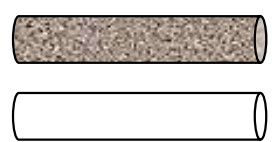

Sand layer applied at one side of the capsules

Figure 1 - Various surface treatments applied onto the PMMA capsules. 


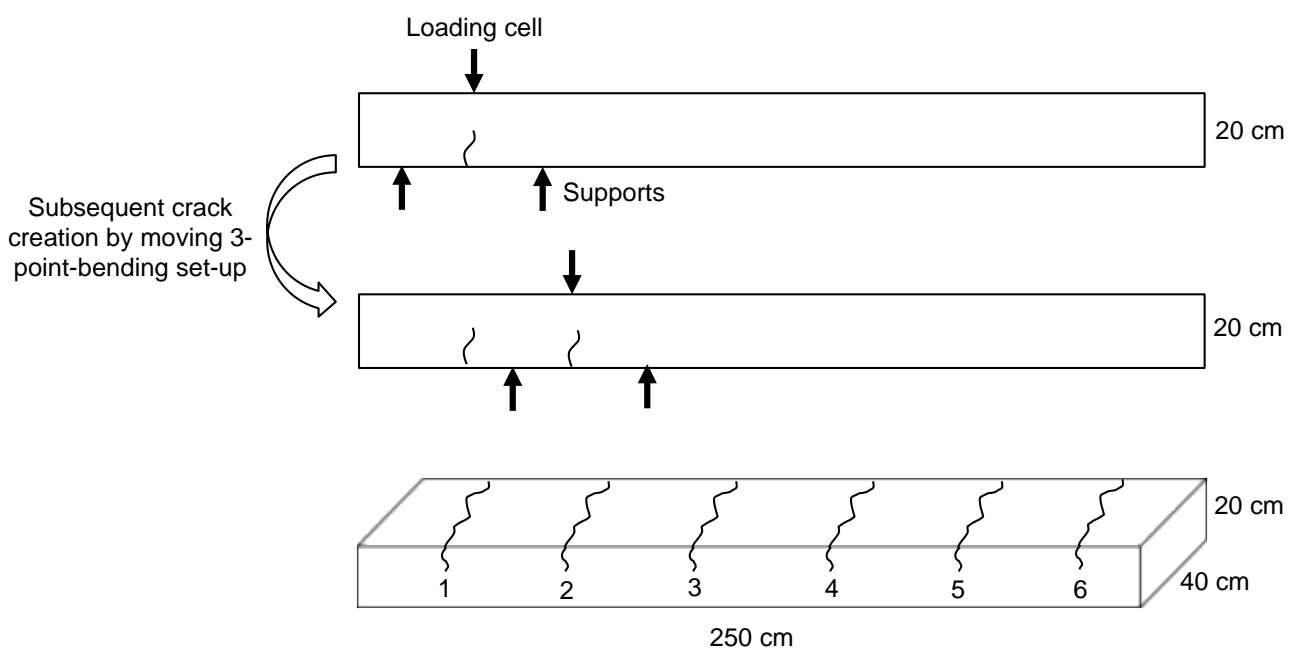

Figure 2 - Schematic representation of the test set-up of the 3-point bending test.

709
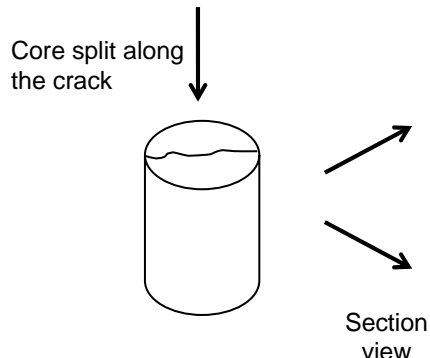

710

Figure 3 - Grinding method to collect powder for potentiometric titrations.

712

A

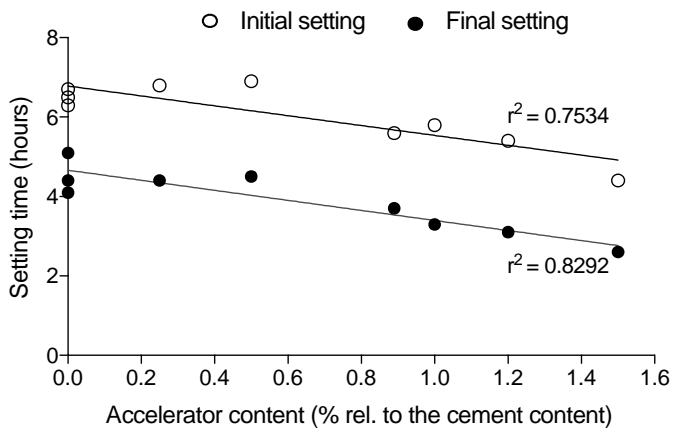

B

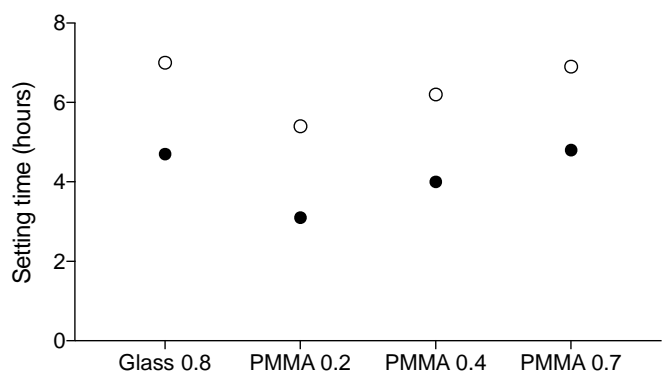

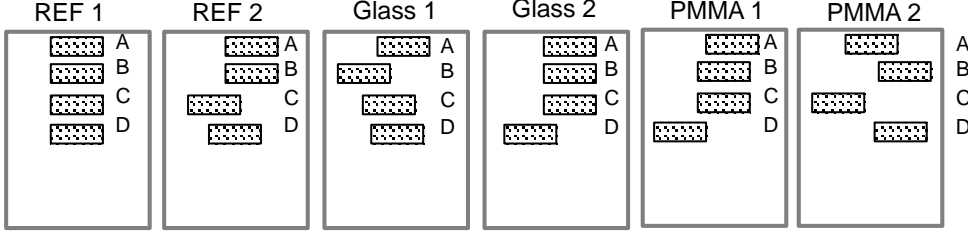

Ground surfaces from the crack face perpendicular to the longitudinal axis of the sample)

714 Figure 4 - Calibration curve showing the influence of the accelerator dosage on the initial and

715 final setting time of SCC concrete (A); Initial and final setting time for SCC mixes containing

716 different types of capsules with $1 \mathrm{~m} \%$ accelerator $(B)$. Glass $0.8=$ glass capsules wall 717 thickness 0.8 mm; PMMA 0.2, 0.4 and 0.7 = PMMA capsules wall thickness $0.2,0.4$ and 0.7 $\mathrm{mm}$, respectively. 
A

720

721 Figure 5 - Calibration curve showing the influence of the accelerator dosage on the evolution of the ultrasonic P-wave velocity (UPV) of SCC concrete (A); UPV for SCC mixes containing 723 different types of capsules with $1 \mathrm{~m} \%$ accelerator (B).

724

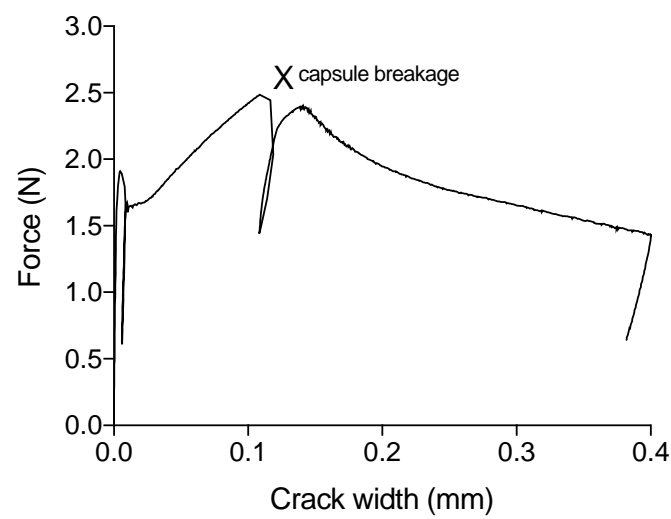

725

726 Figure 6 - Example of load drop due to rupture of the capsule during the three-point-bending 727 test.

728

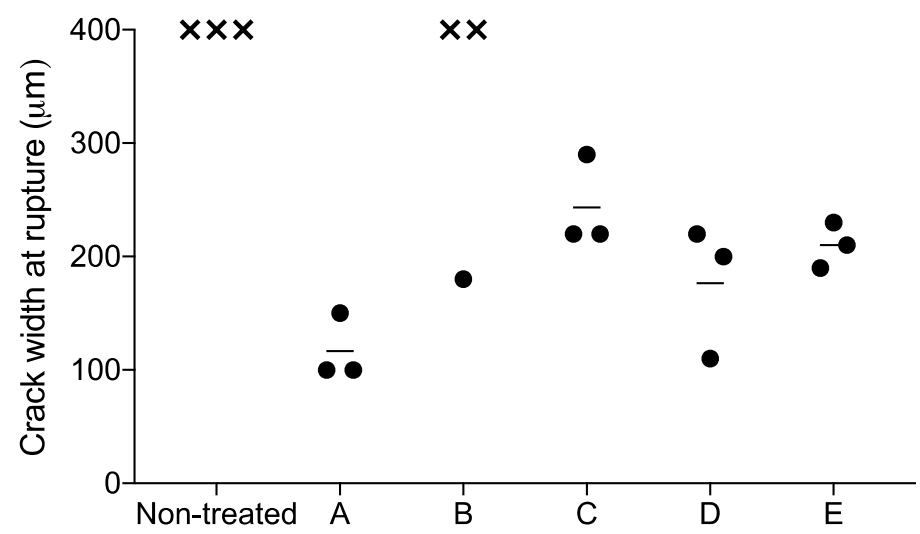


730 Figure 7 - Crack width at breakage of the PMMA capsules as a function of different surface 731 treatments $(\bullet)$, no rupture before a crack width reaches $400 \mu \mathrm{m}(\mathrm{x})$, mean value $(-)$.

A

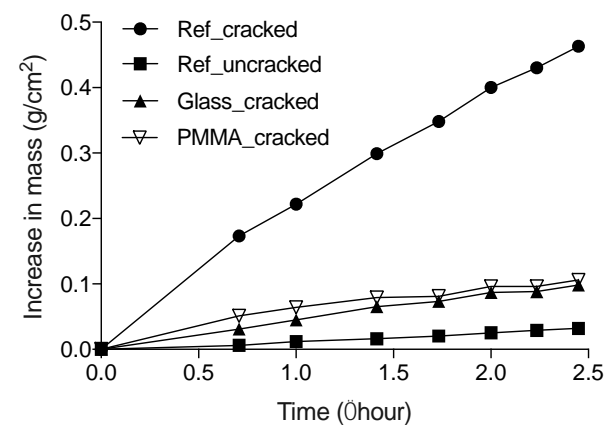

B

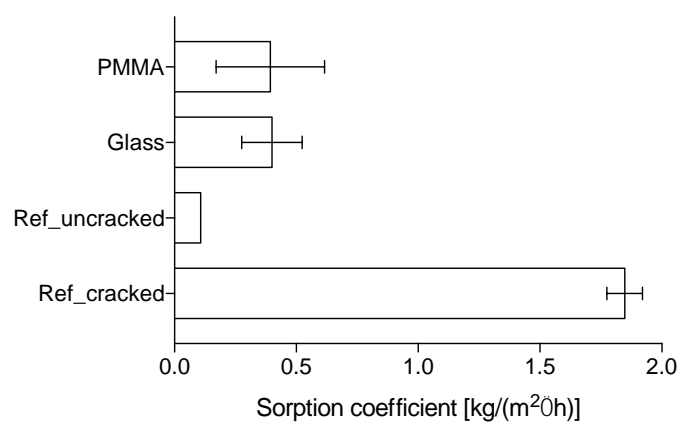

733

734

735

736

A

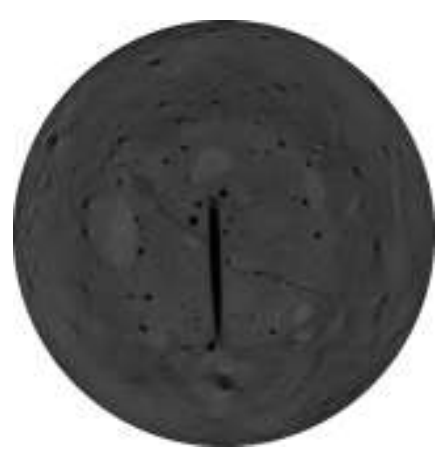

B

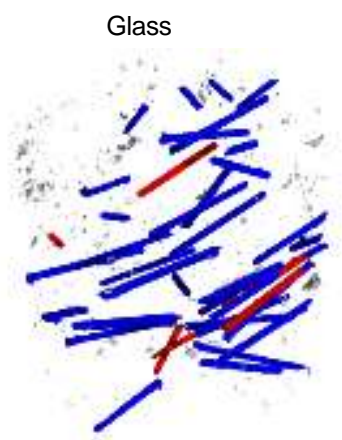

Figure 8 - Mean water absorption as a function of the square root of time $(A)$ and the sorption coefficient $(B)$ for each of the series. Error bars represent the standard error $(n=2-3)$.

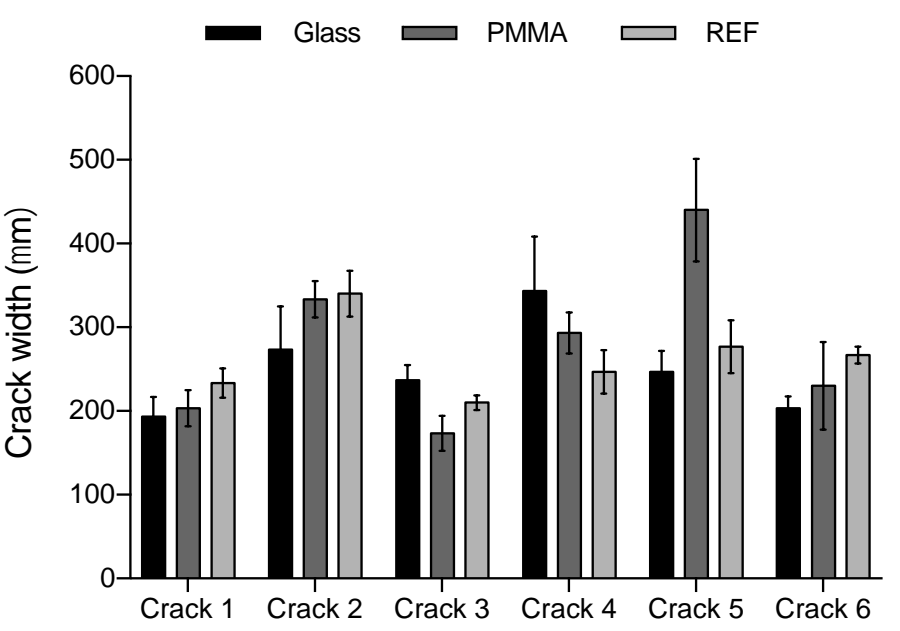

Figure 9 - Average crack width measured at the crack mouth for each beam.

741 Figure 10 - Reconstructed CT of a sample with a glass capsule crossed by a crack (A);

742 Rendered 3D image of the concrete cores with dispersed capsules (B). 


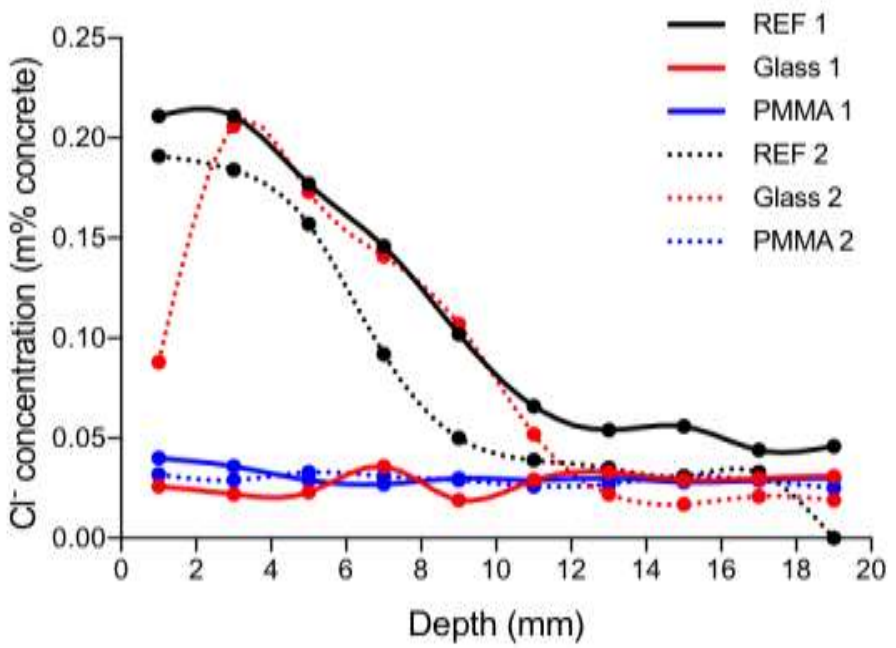

Figure 11 - Chloride profiles in the vicinity of the exposed surface (zone T) obtained after 24

$746 \mathrm{~h}$ exposure to a $3 \mathrm{wt} \% \mathrm{NaCl}$ solution for a time span of 6 weeks.
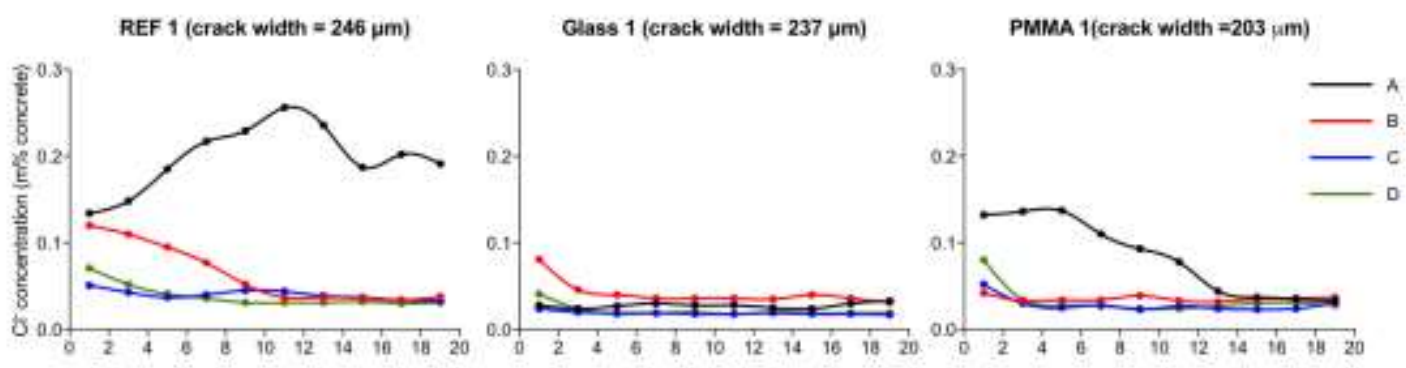

REF 2 (crack width $=340 \mu \mathrm{m})$

Glass 2 (Crack width $=343 \mu \mathrm{m})$
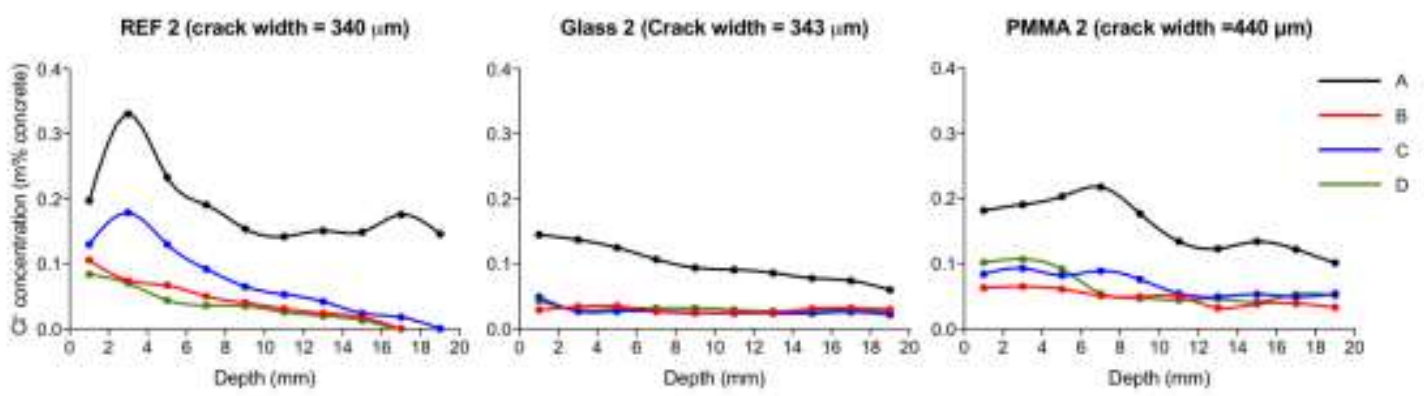

749 Figure 12 - Chloride profiles in the cracked surface obtained after $24 \mathrm{~h}$ exposure to a 3 wt\%

$750 \mathrm{NaCl}$ solution for a time span of 6 weeks. 


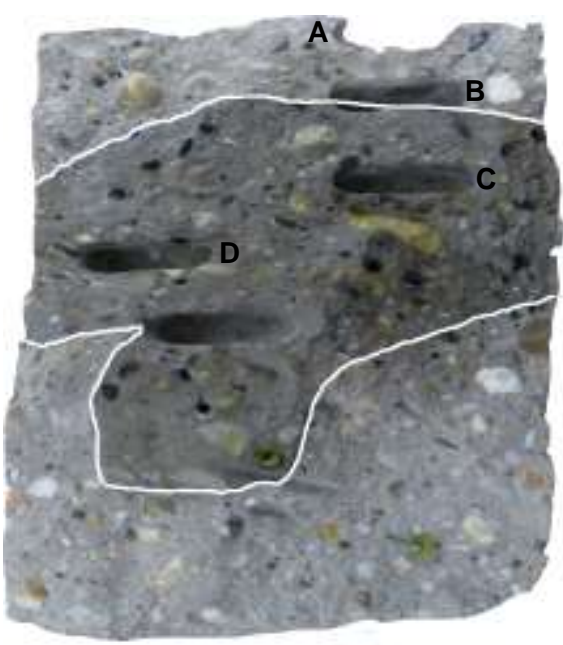

753 Figure 13 - Split cracked plane of a concrete core (Glass 2), with indication of the ground 754 surfaces. White line indicates the area spread with WRA.

755

756

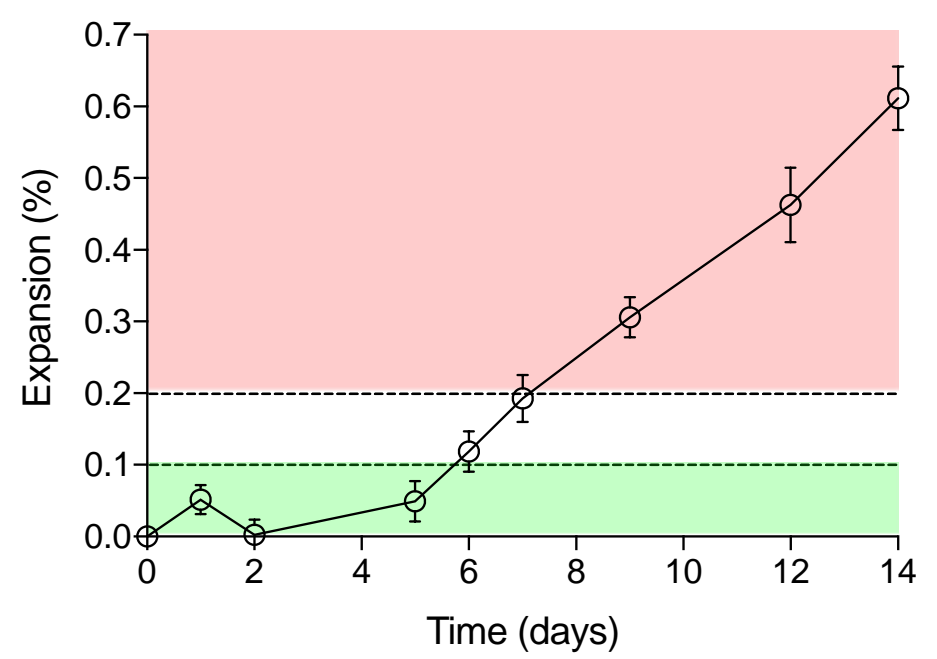

757

758 Figure 14 - Evolution of the average expansion of the concrete cylinders containing glass

759 capsules, exposed to a $1 \mathrm{M} \mathrm{NaOH}$ solution at $80 \stackrel{\circ}{\circ}$ for 14 days. The error bars represent the 760 standard error $(n=6)$.

761

762

763

764

765

766 